\title{
CAPITAL CITY: HOW BILLIONAIRE HEROISM MEDIATES POST-IMPERIAL AMBIGUITIES IN THE AVENGERS AND THE AVENGERS - AGE OF ULTRON
}

\begin{abstract}
This article discusses the negotiation of cultural, economic and political ambiguities in the first two instalments of the Avengers movie franchise. Based on Douglas Kellner's concept of the media spectacle and Dan Hassler-Forest's observations on capitalist superheroes in the neoliberal age, the analysis traces the role of concentrated wealth and futuristic technologies in defeating the otherized forces that threaten the US-American metropolis in both these films. The spectacle-laden struggles are also investigated in terms of their resurrection of national mythologies, which celebrate visions of white, masculine entrepreneurialism and the aesthetics of an imaginary past located in the midtwentieth century. These threads are tied together and put into historical context in two separate close readings of the filmic texts.
\end{abstract}

Key words: superhero, marvel, cinema, ambiguity, city

\section{Introduction}

Superhero movies have emerged as the principal narrative format for bigbudget Hollywood film productions in the early twenty-first century. The ongoing commercial success of these mass media spectacles is augmented by their inscription into numerous, distinctly US-American mythologies that are nevertheless relatable to global audiences (Hassler-Forest 2012: 11). Moreover, Hollywood superhero films are now integrated within a vast framework of elaborate franchises, reboots and remakes, which bolsters their cross-generational appeal and cements their status as branded commodities (Nielsen 2017: 1). The most notable example is the "Marvel Cinematic Universe", which journalist Todd Van Der Werff (2016) has described as "the world's most expensive TV show". Therefore, this highly visible and heavily marketed subgenre of blockbuster movies resides at the intersection of various political, economic and cultural discourses that have shaped media landscapes within the United States and across the world.

These discourses have arisen in a set of contexts marked by the post-9/11 experience, the ensuing so-called "War on Terror", the aftermath of the global

\footnotetext{
* Institut für Anglistik und Amerikanistik, Humboldt-Universität zu Berlin, Unter den Linden 6, 10117
} Berlin, Germany; e-mail: ilias.benmna@gmail.com 
financial meltdown in 2008, and the ongoing digitalization of all spheres of life. These developments are marked by a common theme of open-endedness and irresolution, which can rightly be understood as ambiguities. The status of superhero movies as all-encompassing cultural phenomena (Kellner 2003: 11-15) makes it important to investigate their role in negotiating these social and geopolitical contexts. It is my argument that these cinematic spectacles frequently oscillate between acknowledging certain contradictions of late capitalism in terms of race, gender and space (Fleming 2015: 30), while simultaneously showing little interest in imagining a world beyond neoliberalism and neoconservatism (Hassler-Forest 2012: 240-246). The resulting ideological gray areas form a set of "contested terrains" (Kellner 1995: 55), which emphasize the open-endedness of history while also adhering to the traditional patterns of "American exceptionalism".

A primary example of the cinematic negotiation of this open-endedness is the flagship franchise of the Marvel Cinematic Universe: The Avengers. This crossover spectacle (Gruenewald 2018: 150) of multiple Marvel comic book heroines and heroes offers insights into several layers of economic, domestic, and geopolitical insecurities, which continue to shape socio-cultural discourse in the United States: the unfettered accumulation of wealth in the hands of few individuals, the safety of the urban space in the post-9/11 climate, and the perception of the US-led "Terror War" (Kellner 2009: 127) at home and abroad ${ }^{1}$. These topics intersect in The Avengers in an explicit a well as subtextual manner. Given the global popularity of this franchise, it is vital to ask how the Avengers movies incorporate both criticisms and affirmations of US-American neoliberalism, militarism, imagined national unity and computerized warfare. Central to this cinematic negotiation process are visions of an entrepreneurial and technologydriven reboot of a nation that has encountered its economic and geopolitical limits in the early twenty-first century.

As a first step, I will investigate the depiction of billionaire heroism in conjunction with post-industrial technologies, and the portrayal of the threatened urban space in The Avengers (2012). Building on this initial analysis, I will then trace and discuss the evolution of these themes in The Avengers - Age of Ultron (2015). This inquiry will allow me to build a narrative arc, which reveals the fundamental ideological trajectories of this film franchise ${ }^{2}$. This arc will include the film's approach toward

${ }^{1}$ In his article 9/11, Spectacles of Terror, and Media Manipulation: A Critique of Jihadist and Bush Media Politics, Douglas Kellner argues that term "Terror" is better suited to capture the militaristic excesses of the Bush administration in their execution of the so-called "War on Terror" (2009: 127).

2 The analysis of Age of Ultron will take up a larger part of this article, as it will incorporate discussions on the intensification of topics discussed in the first film. Furthermore, the cinematic strategies for negotiating socio-cultural disruptions can be better illuminated by looking at the sequel and its treatment of the geopolitical developments in the intervening years between 2012 and 2015 . 
domestic political polarization, the primacy of digital technology and its portrayal as both menacing (in the case of Ultron) and supposedly humane (in the neoconservative fantasy of a supposedly "clean war"). Ultimately, the filmic treatment of these topics reveals that a variety of insecurities and doubts about the status of US-American hegemony are transformed into enjoyable entertainment (Bograd 2015: 150) with mass appeal around the globe.

It should be noted that this analysis will not include the most recent instalments of the Avengers franchise: Infinity War (2018) and Endgame (2019). The reasons for this are rooted, firstly, in access to and availability of these films. Secondly, a certain temporal distance to these filmic texts is required in order to carry out the form of diagnostic critique (Kellner 2003: 17) that this article seeks to provide; i.e. examine specific cultural and political reverberations and place the movies in a larger historical context.

\section{Theoretical context}

In this article, I focus on the aspect of "post-imperial ambiguities", since themes of ambivalence and unstable collective and personal identities are recurring features of contemporary superhero movies (Hassler-Forest 2012: 39-43; Žižek 2009: 43). The term "post-imperial ambiguities" is defined here not merely as an observable decline in political, cultural and economic power on the global stage, but also as a discursive setting in which the contradictions of late capitalism become more manifest and irreconcilable on a domestic and global scale. Luke Strongman notes in this context that "the inter-[global] connectivity of discursive forms paradoxically works towards defining national boundaries as at the same time it dissolves them" (1996: no page).

Therefore, I will examine how mainly white, masculine superheroes save the post $9 / 11$ metropolis from attacks by a foreign other and, thereby, mediate a variety of anxieties related to race, class, gender and space. The theoretical framework of my analysis is grounded in Dan Hassler-Forest's discussion of "capitalist superheroes" as embodiments of an intensified neoliberalism and punitive neoconservatism (2012: 1-19). In addition, Douglas Kellner's concept of the "media spectacle" (2003: 2) will form a basis for outlining the larger socio-cultural repercussions of these profitoriented media phenomena. Furthermore, I draw from Susan Jeffords' concept of the "Hollywood Hard Body" (1994: 24-25), which revolves around the rugged hypermasculine action hero of the 1980s and his role in visualizing notions of a jingoistic comeback. 


\section{The Avengers (2012)}

\subsection{Setting the stage: Billionaires to the rescue!}

The late capitalist setting of the United States in the early twenty-first century is marked by the continuous concentration of wealth and economic power in few hands. Especially the corporatized media and entertainment sector, which produces and distributes the bulk of superhero movies, has seen a wave of mergers and acquisitions since the 1980s. This has had profound repercussions not only for the production of such films, but also for their content. In his book Media Spectacle, Douglas Kellner posits that

[t]he synthesis of global corporate capitalism and information and entertainment technologies is constructing novel forms of society and culture, controlled by capital and with global reach [...] The result is a spectacularization of politics, of culture, and of consciousness, as media multiply and new forms of culture colonize consciousness and everyday life, generating novel forms of struggle and resistance (Kellner 2003: 14).

Kellner makes these observations in light of technological transformations that continue to shape the media landscapes in post-industrial societies, leading to an increased emphasis on individualized consumption. This is further expressed in the proliferation of cultural fantasies that offer escapist visions in which the complexities of the world are resolved through spectacular feats of high-tech heroism (2003: 1516). These economic, technological and cultural developments have set the stage for narratives, which center protagonists, who command the necessary capital to effectuate these spectacles.

\subsection{Saving the post-9/11 city in The Avengers}

Throughout numerous superhero movies of the early twenty-first century, the postmodern megalopolis features as a critical site for operations and battles between "good vs evil" (Hassler-Forest 2012: 113-156). New York City often comes to represent the side of the protagonists, who fend off invasions or attempted attacks against the city. This focus on the Big Apple is telling, as the city occupies a central spatial and symbolic position in real-life events that have called the global power of the United States into question in recent decades (Foster 2013: 18). For example: the 9/11 terror attacks, the 2008 financial crash, and the Occupy Wall Street movement. The resulting economic anxieties, security concerns and questions revolving around the so-called "War on Terror" arguably stand in a semiotic relationship with the fate of 
this city. Therefore, New York City offers a unique narrative space for the imaginary resurrection of the US-American might and the negotiation of associated national traumas.

This is also prominent in the first Avengers movie. The feature was released in 2012 and parts of the filming took place in late 2011 in downtown Manhattan with the Occupy Wall Street protests happening in the near vicinity (Milkman 2017: 1-31). Yet, this film drafts a high-tech billionaire as one of the most important savior figures for the city and - by extension - for the nation: Tony Stark. The origin story of this quippy playboy entrepreneur is laden with subtexts of a post-traumatic patriotic rebound. Stark originally made a fortune in the defense and aviation business, and he managed to create an impenetrable flight suit while being held captive by the Taliban in Afghanistan in the first Iron Man movie. Much like the hard-bodied Vietnam war movie hero of the Reagan era, he reverses the course of history by outsmarting heavily armed Taliban soldiers, who are incapable of stopping Stark's high-tech ingenuity and lone-wolf guerilla tactics (Jeffords 1994: 28-39). This performance of a previously victimized, but now resurgent masculinity parallels mass media discourses surrounding the "healing of a wounded nation". These narrative strategies abounded in mass media not only after the 9/11 attacks, but also in the later years of the disastrous war in Iraq, which revealed the shortcomings of the neoconservative policies of the Bush administration (Kellner 2009: 219-233). Susan Jeffords notes in this context that cinematic visions of indestructible masculine hard bodies offer a suitable vehicle for conveying a sense of wish fulfilment in a time of national doubt: " [...] the pleasure of feeling a part of national unity could be achieved, not through a speech, a flag, or even a war, but through the narration and movement of hard bodies themselves - their confrontations, actions, decisions, and victories" (Jeffords 1994: 27).

Furthermore, the space through which superheroes navigate is critical in understanding the underlying anxieties they address. While the first Iron Man movie - which is mainly set in Afghanistan - came out in 2007, at the height of the Iraq War, The Avengers revisits New York City after the global financial crisis and the election of Barack Obama in 2008. At the beginning of the film, it is shown that Tony Stark has made Manhattan his home again. There he resides in a branded futuristic skyscraper, Stark Tower, which reigns supreme throughout the skyline of the city. His tower is in visible proximity to the Chrysler Building, which positions Stark and his enterprise in the neighborhood of an iconic symbol of early modern industrial capitalism. The physical resemblance between Stark Tower and the nearby Chrysler Building offers a visual genealogy, which inscribes the modern-day superhero billionaire into mythologies of national strength brought about by imagined entrepreneurial genius (Ranogajec 2018: no page). This is a crucial element for the post-imperial subtext in 
The Avengers, as Stark Tower can be read as a resurrection of the Twin Towers that were destroyed in the $9 / 11$ attacks.

However, unlike the former World Trade Center, the highly personalized Stark Tower is also clearly linked to a recognizable symbol of industrial capitalism, which constitutes a much longer historical arc and a deeper reach into mainstream mythologies of the free enterprise system as a supposed driver of global US-American strength. In his analysis of post-9/11 cultural fantasies of war, Leo Braudy notes that the remasculinization of "mercantile culture" is a central element in negotiating the collective trauma suffered in the attacks on Manhattan in 2001 (Braudy 2003: 464). The notion of a national reboot based on accentuated images of hyper-capitalist and hyper-masculine strength points to the centrality of both nostalgic and neoliberal myths in constructing the post-traumatic city in The Avengers. The post-imperial doubts in the aftermath of the 9/11 attacks and the monumental failures of finance capital in 2008 are submerged in a vision that combines an imaginary past with a highly individualized and consumption-oriented future. Discourses on the role of workers in constructing these monuments to national strength are entirely absent from the film, which exposes a telling gap regarding the representation of the working class in the neoliberal megalopolis (Hassler-Forest 2012: 147-156).

In this context, it should be noted that the movie offers a certain measure of gendered and racial diversity. For example, the Russian spy-agent Natasha Romanoff is a vital member of the Avengers team and the African American Nick Fury is the head of the agency S.H.I.E.L.D., which oversees the actions of the motley crew of superheroes. Fury's authority is, however, repeatedly called into question by Tony Stark, who suspects the head of the agency to be hiding secrets from the Avengers (Moon 2016: 34). This racist unease with Black leadership shows parallels to the attacks mounted against Barack Obama during his first term in office. Interestingly, Tony Stark's efforts to accuse a Black authority figure of being duplicitous and untrustworthy parallel the attempts of another real-life New York City billionaire in 2011 (Zakaria 2011: no page).

Eventually, the fate of the urban space in The Avengers remains centered on the status symbol of the entrepreneur. This becomes evident when the antagonist in the movie, the villainous demi-god Loki, invites an invasion of planet Earth by an alien race called the Chitauri. The intergalactic portal, though which these otherized foreigners enter the atmosphere, is located exactly on top of Stark Tower in Manhattan. This specific locale is, therefore, not only testament to a supposed entrepreneurial genius, but it also becomes a cosmic battleground in the defense of the nation.

In the final struggle between the Chitauri and the Avengers, the city is subjected to scenes of chaos and widespread destruction. Most male members of the Avengers 
sport superhuman advantages that allow them to traverse the urban space very quickly and without being bound by gravity. For instance, the Hulk climbs up and jumps his way through numerous skyscrapers, showcasing his enormous strength and hypermasculine hard body. The demi-god Thor and Captain America use their superhuman agility and powerful tools to directly confront the invaders in high-paced, mid-air combat scenes. The sole female member of the Avengers, Natasha Romanoff, is afforded less action in comparison. Her lack of superhuman might arguably disqualifies her from being a hard-bodied emblem for an indestructible nation. However, the film tasks her with shutting down the intergalactic portal on top of Stark Tower. It can be argued that this "separate-but-equal" status for Romanoff within the superhero group is evocative of national debates on female participation in U.S. Army combat units in the early 2010s (Murphy 2015: 11-12). This opening up of exclusive heterosexist male spaces is, however, better understood within the paradigms of a post-9/11 "national emergency", in which the imagined struggle against the racialized other takes the form of a seemingly diverse and multicultural city, which is attacked by a uniform and barbaric invading force.

Ultimately, the most engaging spectacles in the final battle scenes belong to the white males, with Tony Stark outpacing all other participants thanks to this Iron Man suit. In a city that appears to be falling apart, Stark plays the double role of defending it not only against alien invaders, but also against an inept domestic bureaucracy. During the final showdown, the agency S.H.I.E.L.D. decides to launch a nuclear missile against Stark Tower in an effort to destroy the portal. This would, however, endanger millions of lives. Stark uses his flight suit to intercept said missile and launch it against the Chitauri mothership in outer space; thereby defeating the aliens and protecting his own personal monument. This happy ending underlines Dan Hassler-Forest's observations on capitalist superheroes in the neoliberal metropolis:

The superhero's powers, which consist either of supernatural physical abilities or of a fantasy of unlimited capital, make him a figure of empowerment and agency in a world of consumers who are defined by their lack of these very qualities. Their crime-stopping ideological agenda is meanwhile a pure distillation of basic capitalist assumptions: the defense of property by punishing "the transgressions but not the conditions that give rise to these transgressions..." (Hassler-Forest 2012: 138)

Therefore, numerous ideological threads converge in the final battle scenes, as the ineptitude of bureaucracy is mediated by capitalist heroism. The performance of superhuman feats offers a form of spectacle escapism in which the city suffers 
destruction not only at the hands of invaders, but also by homegrown heroes and bureaucracies (Kellner 2009: 80-91). Given how the cityscape of Manhattan is constructed as a combination of myth-laden nostalgia and post-modern hyperrealities (Baudrillard 2001: 1732-1741), the final battle in The Avengers offers a spectacle of almost nihilist catharsis in which symbols of the old and new are destroyed, but the fantasy of capitalist genius is upheld. From this angle, it can be deduced that the physical destruction of the urban space is a feasible fantasy in superhero movies. The end of capitalism, however, is not. The lack of ambiguity in this regard is neither new to Hollywood film nor does it represent a deliberate attempt at obfuscation. Instead it highlights the movie's place as a commodity in a corporatized media landscape. Cultural theorist and film critic Robin Wood already made a similar observation in his analysis of the early blockbuster cinema offered by the Star Wars franchise: "Spectacle - the sense of reckless, prodigal extravagance, no expense spared - is essential: the unemployment lines in the world may get longer, we may even have to go out and join them, but if capitalism can still throw out entertainments like Star Wars [...], the system must be basically OK, right?" (Wood 2003: 148).

\section{The Avengers: Age of Ultron (2015)}

\subsection{Setting the stage: Avengers of the world unite!}

The survival of neoliberal capitalism and subsequent celebration of high-tech white male entrepreneurship in The Avengers carries important connotations for the sequel, which was released in 2015. The NSA spying scandal in 2013 (Brody 2015), the annexation of Crimea by the Russian Federation in 2014, and the emergence of the Salafist militant group ISIS/Daesh in the newly erupted civil wars in Iraq and Syria reignited global discussions about the global standing of the United States. The related widespread unease with digital surveillance and monitoring technologies, coupled with the erosion of imperialist projects abroad was augmented by growing political divisions within the United States, as evidenced by the rise of the Tea Party (HasslerForest 2012: 259) and new forms of social-media-based grassroots activism ${ }^{3}$.

Considering these developments, it is necessary to read Age of Ultron as a reaction and renewed negotiation of the changing socio-political realities. Three important narrative threads emerge within the parameters of this analysis: Firstly, the role of a conscious and villainous artificial intelligence, which was originally conceived in the laboratories of Stark Enterprise. Secondly, the resulting in-fighting

\footnotetext{
${ }^{3}$ A 2014 poll by the Pew Research Center revealed that the percentage of U.S. citizens, who "express consistently conservative or consistently liberal opinions has doubled over the past two decades from 10\% to 21\%" (Political Polarization in the American Public, June 12 2014)
} 
within the Avengers and their underlying ideological fault lines. Thirdly, the projection of a benevolent imperialism through a high-tech powered "clean war" (Gruenewald 2018: 150-53). All these interrelated storylines take aim at one or several of the aforementioned ambiguities through offering a megaspectacle in which the contradictions of neoliberalism and neoconservatism are resolved through high-tech capitalism and the performance of a post-9/11 patriotic piety.

\subsection{The fragmented benevolent empire in The Avengers: Age of Ultron}

"[T]elling stories about trauma, even though the story can never actually repeat or represent what happened, may partly achieve a certain 'working through'for the victim.

It may also permit a kind of empathic 'sharing' that moves us forward".

E. Ann Kaplan,

Trauma Culture: The Politics of Terror and Loss in Media and Literature (2005: 37)

The film begins with an intervention by the Avengers in the fictional country of Sokovia (located in Eastern Europe), where the superheroes retrieve a magical scepter that belonged to the demi-god Loki. The powerful device was in the hands of the German antagonist Wolfgang von Strucker, who sought to use it for human experimentation in a secret research facility. After its retrieval, Tony Stark and Bruce Banner (the Hulk) recognize the potential of the scepter for harnessing a superior form of artificial intelligence that would catalyze Stark's long-term project of a private global defense system (entitled "Ultron"). In the initial conversation between the two, Stark's drive toward an entrepreneurial solution to the ongoing challenge from otherized supervillains becomes evident:

Tony Stark: "I want to apply this to the Ultron program. But Jarvis can't download a data schematic this dense. We can only do it while we have the scepter here. That's three days. Give me three days".

Bruce Banner: "So you're going for artificial intelligence, and you don't want to tell the team?"

Tony Stark: "Right. That's right. You know why? Because we don't have time for a city hall debate. I don't want to hear 'the man was not meant to meddle' medley. I see a suit of armor around the world".

In this exchange, the theme of entrepreneurial individualism versus a collective effort is amplified as Stark is not only pitting himself against the bureaucracy of S.H.I.E.L.D., but is willing to push ahead with a personal defense vision without even consulting the other Avengers. Stark invokes the vocabulary of a neoliberal disdain 
toward institutionalized public procedure by describing any form of consultation with his teammates as a "city hall debate" (Jeffords 1994: 19). Given the implied juxtaposition between S.H.I.E.L.D. and the Avengers in the first movie, this episode can be interpreted as an expanded move by Stark to monopolize the defense of the nation in his own hands.

Therefore, the underlying trajectories throughout these two films reveals a trend toward the depiction of an increasingly concentrated economic and political power (Wolf-Meyer 2006: 203). This is amplified by a "war-without-end"-scenario in which the "irrational other" reappears in more violent and theatrical ways, fueling a dialectical logic of spectacle and counter-spectacle. Within this framework, the limited economic power of a dwindling middle-class (now also represented by the other Avengers) must yield to the imagined paternal strength of a futuristic and individualist capitalist venture in order to produce the counter-spectacle that can - at least on a psychological level - alleviate the perceived humiliation through belligerent others. This counterspectacle is described by Stark as a "suit of armor around the world" - a Reaganite and neoconservative fantasy that suggests that wars can be preemptively stopped and the United States can be safely secured from the rest of the world (Rogin 1998: 56).

In his attempt to bring about "an end of history", Stark soon realizes that he has unraveled forces which further demonstrate the illogicalities of late capitalism. The experimentation with the scepter's own artificial intelligence leads to Ultron becoming self-aware. Even though Ultron has been tasked with ensuring the safety of planet Earth, he soon concludes through his own research (which he conducts within mere seconds) that only the eradication of humans will bring about ever-lasting peace. Ultron breaks free, relocates to Strucker's facility in Sovokia and begins building his own army of drones. Aided by two of Strucker's previous test subjects - the Maximoff twins - the new villain proceeds to attack the Avengers through physical and psychological means (e.g. by having one of the twins projecting haunting visions into the minds of the protagonists). The renewed attacks on US-American soil are now coupled with the revisiting of previous traumas. This is suitable to suggest that, in the contemporary global climate, shock is a perpetual state of mind and, simultaneously, a megaspectacle that can repeatedly generate mass attention (Plantinga 2009: 49). Thus, the political anxieties of the early twenty-first century remain fuel for a capitalist spectacle logic. For instance, Natalie Kate Bograd states in her analysis of the post-9/11 aesthetic in the Marvel Cinematic Universe that " $[\mathrm{w}]$ hen a traumatic set of images emerges, there is a dual temptation to view them repeatedly in an attempt to make sense of the disaster

\footnotetext{
${ }^{4}$ Carl Plantinga explains the spectator's experience of film in the following terms: "If films approximate conscious experience like no other medium, they do so also in their ability to elicit emotional responses to that experience" (2009: 49).
} 
and a paradoxical desire to avoid them entirely" (2015: 118). This collective need to revisit the spectacle and simultaneously avoid it is evocative of the relationship between "reality" and "virtuality" in Baudrillard's concept of hyperreality; "a reality in which everything has imploded and lost its meaning, there is no distinction between real and unreal" (Kosović 2011: 20; Baudrillard 2001: 1732-1741).

In the film this is expressed through a scene shortly before the first attack, in which the Avengers are hosting a lavish party in Stark Tower. Among the attendees is a WWII veteran, played by the real-life Avengers co-creator Stan Lee, who through his very presence connects the fictional heroes of the present to the celebrated heroes of the past. This is further enhanced by Natasha Romanoff's performance, who acts as a bartender at the party while also playing the role of a Golden Age Hollywood actress. These numerous layers of meta-textuality do not necessarily disintegrate when Ultron storms the tower and starts attacking the Avengers. On the contrary, the temporal and spatial arcs between the war heroes of the old and the superheroes of the present run parallel to the performance of a historical Hollywood 1940s glamor. Much like the soldiers of WWII - and the stylized heroes of 9/11 (Hassler-Forest 2012: 28) - the Avengers are now tasked with responding to the new threat in an undaunted manner, which they do in the ensuing fight.

In this accumulation of simulacra, the semiotic distinction between real and unreal collapses to a degree that mediated representations of e.g. war and violent attacks on civilians assume a video-game-like quality that implies a "sense of control" (Gruenewald 2018: 143). The transferal of traumatic events into the profitable venue of media spectacle, therefore, affirms and caters to collective desires to control the uncontrollable. This makes the spectacle a suitable venue for mediating the anxieties brought about by a shifting geopolitical climate.

The film contains numerous references to these geopolitical insecurities. For instance, the specific Eastern European locale of the attackers - Ultron and the Maximoff twins - latches on to the renewed political tensions between the United States and Russia over the annexation of Crimea in early 2014. The film revisits the general region of this new (and old) challenger to US-American hegemony, giving the opportunity to renegotiate the perceived loss of global dominance in cinematic terms. However, it should be noted that it is Ultron, who installs himself in Sokovia and recruits the Maximoff twins to carry out his nefarious plans. In this sense, a product of the profit-driven US-American military-industrial complex is indirectly responsible for turning a foreign nation into a hub for anti-American activities (Hagley and Harrison 2014: no page). This not only echoes the historical rise of terrorist groups like Al-Qaida or the Taliban in Afghanistan (Hammer and Kellner 2009: 476), but it also mirrors more general concerns about the homegrown military and 
national security state as complicit in the production of violent global conflict. Yet, the relocation of the militarized high-tech threat of Ultron to Eastern Europe also opens gateways for the "orientalization" of violence (Said 2003: 301-302). In this sense, Age of Ultron oscillates between indicting the domestic military apparatus and offering an externalized vision of the global machinations of high-tech surveillance entities. It can be argued that the imperial technologies conceived to contain "the other" have now assumed so much global power that they themselves must be contained.

The characteristics of Ultron as a villainous force and artificial intelligence are, therefore, of interest for this analysis. Much like his creator, Tony Stark, Ultron envisions a world without conflict. However, his unlimited physical and technological capabilities quickly corrupt his view of the world to the point, where he sees the eradications of all humans as the only possible option to ensure global peace. Actor James Spader, who lent his voice to Ultron, summarizes the character's development in an interview:

$[\mathrm{H}] \mathrm{e}$ sees the Avengers as being part of a problem, a more comprehensive problem in the world. [...] [H]e sees the world from a very strange point of view because he's brand new, he's very young [...]. Because he's been able to upload an enormous amount of intelligence and so on, and that's also been fed into him as well.

So he's immature, and yet has knowledge of comprehensive, broad history and precedent, and he has created in a very short period of time a rather skewed worldview. Which is certainly not unprecedented! He's probably self-absorbed (Lee 2014).

Essentially, Spader describes an exponential development in terms of technology, knowledge and scope, which has not been matched by an appropriate cultivation of morality and ethical guidelines. The recent proliferation of digital technologies with the potential for mass surveillance on a global scale - through both corporate and state actors - can be described in similar terms, giving weight to the argument that the overreach of the US-American national security state and tech giants like Google and Facebook is creating new ambiguities and, in fact, anxieties and open backlash ${ }^{5}$. The rapid accumulation of data has now assumed the status of a superweapon, which - in the logic of the film - can only be curbed by the Avengers. At one point in the film, Ultron himself comments on the irony that he was created by Stark Enterprises and is

\footnotetext{
${ }^{5}$ For example, the transatlantic coordinator for the German Foreign Office, Philipp Mißfelder, commented on the NSA scandal by saying that "the current situation in transatlantic relations is worse than it was at the low-point in 2003 during the Iraq War" (Kosal 2018: 272).
} 
now set to destroy the Avengers ("Everyone creates the thing they dread. Men of peace create engines of war. Invaders create Avengers. People create [...] smaller people? Children!").

Ultron ties several threads of a purported cyclicality of innovation and destruction together. He postulates that, almost in a Marxist-Hegelian sense, any accumulation of power and knowledge creates the conditions for its displacement. This doesn't only affect the military state ("Invaders"), but also humans at large ("People create [...] smaller people"). Numerous associations can be evoked from this statement. These include the post-Fordist nature of Ultron and how the increasing digital automation is now threatening the displacement of workers even in high-tech workplaces (Cox 2018: 5-6). However, within the parameters of this analysis, it can be observed that Ultron is offering a mythical explanation for a "perpetual war", in which conflict is naturalized and decontextualized as an ongoing response and counter-response between warring factions. Thereby, his ruminations pick up on existing anxieties and geopolitical insecurities by inscribing them into a mythical circle of naturalized violence. His vision appears bleak from the vantage point of U.S. hegemony, as he implies that it is the very nature of empires to be displaced. Yet, it is the Avengers that restore the status quo when they ultimately destroy Ultron in the final battle. This breaks the proposed cyclicality of history and reinstalls a certain sense of linearity for human progress.

However, this is a linearity that aligns with the serialized aspects of the Marvel Cinematic Universe, i.e. progress also includes the abandoning of previously held (mythical) truths. In one of the final scenes, Captain America and Tony Stark discuss how to go on with their lives after the final battle:

Captain America: "The simple life".

Tony Stark: "You'll get there one day".

Captain America: "I don't know. Family, stability [...] the guy who wanted all that went into the ice 75 years ago. I think someone else came out".

This brief conversation reveals a number of subtexts that indicate how Captain America, one of the premier symbols for the status of the US-American empire, has come to realize that there is a need for readjustment in the new geopolitical realities of the 2010s. His confident demeanor while giving his line about leaving "family" and "stability" in the past indicates a reevaluation of the nostalgic myths that are central to his character. The signifiers of the post-WWII white middle-class setting are now described as an abandoned historic idyll (Schulz 2013: 23-24). This reinforces the functioning of these signifiers as anchoring nostalgic myths for contemporary 
discourses; the normative "American dream" of the twentieth century, which already excluded huge portions of the U.S. population at the time, now appears less attainable in a time of fundamental economic and political transformations, which may signal the end of the "American century". However, Captain America phrases this as a desirable outcome of self-evaluation and personal journey ("the guy who wanted all that went into the ice 75 years ago"). The reorientation toward new realities does not include the deconstruction of national mythologies, leaving their basic ideological location intact. In other words, US-American imperialism is embracing an age of new challenges not because it must, but because this embrace is the outcome of a voluntary transformation. Existing political ambiguities are thereby negotiated within a language of progress and self-reflection. This happens without ever negating the motivating power of past myths. Roland Barthes describes the underlying dynamics of such a recycling of myths in the following terms:

In fact, metalanguage constitutes a kind of preserve for myth. Men do not have with myth a relationship based on truth but on use: they depoliticize according to their needs. Some mythical objects are left dormant for a time; they are then no more than vague mythical schemata whose political load seems almost neutral. But this indicates only that their situation has brought this about, not that their structure is different (Barthes 1972: 144).

The conversation between Captain America and Tony Stark points to a recalibration of collective psychological desires among the movie-going public. The focus appears not so much on domestic restoration in the face of foreign challengers - as was the case in the first Avengers movie - but on incorporating and mediating the disruptive forces that challenge US-American hegemony from within. This is further exemplified in one of the most spectacle-laden scenes of Age of Ultron: the battle between Iron Man and the Hulk in Johannesburg, South Africa.

This fight scene erupts when Ultron launches his second attempt to destroy the Avengers ${ }^{6}$. After the first failed attempt, Ultron recruits the Maximoff twins, who sport special physical and telekinetic superpowers ${ }^{7}$. Wanda Maximoff uses her psychological abilities to induce traumatic visions into the minds of the Avengers; each one of them confronting a certain member with unresolved issues of their past. This

\footnotetext{
${ }^{6}$ This happens during a stint in South Africa, where Ultron is trying to obtain the weapons resources for his plans.

${ }^{7}$ The twins had been orphaned in a war during which their parents were killed by US-supplied weapons that had been produced by Stark Enterprises. As a result, they harbor a deep resentment against Tony Stark, his company and any form of U.S. involvement in their country of Sokovia. This backstory is another acknowledgement of the so-called "blowback" to hegemonial projects by the military-industrial complex - in this case personified through Stark Enterprise (Hagley and Harrison 2014).
} 
visual re-experiencing of the past leads to visceral reactions among the superheroes; revealing that there are psychological rifts within this close-knit group that can erupt in bombastic violence. In his essay 9/11, Spectacles of Terror, and Media Manipulation, Douglas Kellner notes that "[s]pectacles of terror thus use dramatic images and montage to catch attention, hoping thereby to catalyze unanticipated events that will spread further terror through domestic populations" (Kellner 2003: 3).

This well-orchestrated theater of "psychological terror" achieves the effect that Ultron and the Maximoff twins desire. Scientist Bruce Banner loses control over his temper and transforms into the uncontrollable Hulk. The green giant proceeds to descend onto downtown Johannesburg and wreak havoc on the city. The police forces are incapable of stopping the Hulk when suddenly Iron Man intervenes from the sky. The following destructive spectacle bears a striking similarity to the final battle of the first movie. Only that this time, it is one Avenger trying to prevent another Avenger from completely devastating a major metropolis. The threat is once again homegrown and the result of military experimentation. In the elaborate and violent clashes between the two, the Hulk's raw physical power is confronted by Tony Stark's finely tuned hightech gimmicks, which repeatedly manage to contain the Hulk temporarily. This appears as a momentary vindication of the neoconservative fantasy of the "clean war" - a post9/11 sense of control, in which the terrorizing other can be clinically incapacitated by using targeted technology and avoiding civilian casualties (Gruenewald 145-147) ${ }^{8}$. Iron Man, indeed, manages to deliver on one key element of the "clean war": through his acrobatic feats - accompanied by high levels of destruction to buildings and infrastructure - the iron-clad superhero keeps the Hulk's focus on him and away from the fleeing civilians. At one point, he even manages to catch an elevator in mid-fall, so that the passengers can exit unharmed.

Nevertheless, the raw and primal force of the Hulk cannot be fully contained by Stark's technology without resorting to dramatic action. In a scene, which is highly reminiscent of the collapsing Twin Towers on 9/11, Iron Man drops the Hulk onto a skyscraper structure (of course after scanning the structure for potential bio signs and confirming that there are none). He then proceeds to fly into the building with full armor and follow the falling Hulk, leading to the collapse of the entire building. The subsequent smoke clouds emanating from the site and the shaky, wide-angle shots of people frantically running through the streets evoke the tense atmosphere of $9 / 11$.

What is interesting in this revisitation of real-life destruction is that U.S. military technology is presented as ambiguous in terms of containing the terrorist threat (Stark

\footnotetext{
${ }^{8}$ In his essay Superhero Films after 9/11, Tim Gruenewald explains that "[j] ust as the U.S. military staged a visual spectacle of targeted bombings in the service of preventing civilian deaths, superhero films present "technologies" of superpowers, which could be read as allegories for U.S. military technology" (2018: 146).
} 
needs to resort to desperate measures despite his technological advantage). However, the film takes an uncompromising stance on the ability of Stark's technology to safeguard and protect those bodies that are marked as civilian and therefore "innocent". Especially given the fact that this presents an intervention in a foreign country, the unwavering bloodless stance of the film provides cues about the cinematic portrayal of the United States as a humane empire that ultimately respects the sanctity of life and conducts its wars in a spectacular, but "family-friendly" way. Natalie Kate Bograd states in this respect that "[t]he bloodless nature and cartoon violence that define the MCU's destructive spectacles strips these sequences of their traumatic potential" (2015: 131). In this case, the fictional theater of destruction in Age of Ultron parlays the real-life traumas of war and terrorism into a mass compatible affirmation of an admittedly flawed but ultimately benevolent imperialism.

In the context of the "Terror War" and the drone warfare of the Obama era, this assumes a hyperreal dimension as the Avengers movies recreate the aesthetics of real-life destruction, but ultimately also effectuate the empty and misleading promises of political leaders, who claim that empire-building measures around the globe come without any civilian costs. Not only does this lack of ambiguity align with neoconservative fantasies, but it also evidences its integration within a late capitalist entertainment logic, in which the spectacle is repeatedly staged and reframed. In a time of remakes, sequels and cinematic universes, the spectacle remains open-ended and "rebootable" (Bograd 2015: 132). This means that the very lack of ambiguity, that death represents, needs to be minimized or completely eclipsed. Therefore, Age of Ultron illustrates an additional certainty to the survival of capitalism that the first movie has shown: that the empire is ultimately benevolent. A consumption-oriented and masculine high-tech capitalism will win the day and provide the empire with the tools to claim moral superiority in a global age of uncertainty. The empire, in turn, generates new testing grounds and markets for high-tech development, as the unstable regions create demand for new weaponry. In this sense, neoliberal capitalism and neoconservative interventionism continue to reinforce each other - both on and off the screen.

\section{Conclusion}

The analyses of both films have evidenced that the meta-structures of USAmerican neoliberalism and neoconservatism are vital anchors for elucidating the ideological subtexts of the filmic narratives. In both cases, the storylines revolve around salvaging a status quo that is repeatedly disrupted, not only by otherized forces, but also by economic, political technological dynamics that appear to be inevitable by-products of neoliberal and neoconservative projects. The resulting contradictions are worked into a set of mass compatible spectacles, which offer a form of on-screen 
catharsis. However, the underlying ambiguities of the early twenty-first century - both on the global and domestic level - are chiefly mediated through the use of conventional Hollywood tropes that center white masculinity, e.g. the hard body, or through reference to distinctive US-American mythologies that evoke a stylized nostalgia for the midtwentieth-century as an anchoring point for national identity.

First and foremost, the high-tech capabilities of billionaire Tony Stark emerge as a centrifugal vehicle for maintaining US-American global dominance and erasing doubts regarding the validity of entrepreneurial capitalism in the post-financial-crash era. The recourse to mythical imagery in safeguarding an image of military and economic potency intersects with Roland Barthes' observations on myths as "depoliticized speech" (1972: 142-145). The usage of naturalized, mythical images was shown to be prevalent throughout both movies. For instance, the nostalgia-laden character Captain America performs as a messenger of an imaginary past, built around the motivating middle-class imagery of the post-WWII "American dream". Yet, in Age of Ultron, he announces his departure from this mythology without interrogating its normative status. It can be argued that, even though the myths of the old remain intact, they are also (partially) retired in light of the reshuffled social and economic realities. This allows for a linear telling of history in a film franchise that is predicated on open endings and sequelization (McEnteggart 2010: 171-189). This merger between profitable blockbuster formulas and mainstream political anxieties offers insights into the ideological corridors of the Avengers franchise and the Marvel Cinematic Universe at large.

The real-life disruptions in the form of endless wars in the Middle East, geopolitical blowback, terrorist attacks, mass surveillance through government and corporate entities (Kellner 2009: 163-195) are touched upon within the films and given a context that can be aptly read as subtle critiques of unfettered capitalism and the "Terror War". This is especially true for Age of Ultron, which features two antagonists who have been orphaned by US-made weapons, a villainous artificial intelligence that resulted from Tony Stark's private military technology ventures, and physical altercations among the superheroes themselves. However, the remedy to these challenges remains within the confines of a neoliberal framework that suggests US-American technologies can fight wars without casualties (Gruenewald 2018: 150153), that (white, male) entrepreneurial ingenuity will deliver the technologies that can counter novel threats (which in turn implies a further concentration of wealth and power) and that the private vigilantism of the protagonists trounces all available alternatives for collective peacekeeping or judicial due process (no "city hall debates"). Collective insecurities thereby become another vehicle for marketable spectacles that reinforce the contemporary flow of wealth and power. The constant revisitation of real-life theaters of destruction was shown to cater to collective psychological needs 
for processing traumas (Kellner 2009: 99-101; Bograd 2015: 128-132). This provides content for a serialized mass entertainment that has become more prevalent in the digital age. Therefore, the social functioning of superhero spectacles as perpetual simulacra was found to be a central characteristic of their internal logic, which should provide food for further thought.

Furthermore, it can be observed that the bodies of racialized minorities and of women (most notably Natasha Romanoff and Nick Fury) remain deprived of a pivotal role in unleashing the cathartic dynamics that defeat the invaders in the final spectacles (Fleming 2015: 56). Nick Fury is upstaged by the much more prominent and intrepid Tony Stark, who also voices racist suspicions against him. Natasha Romanoff lacks the critical superpowers that would allow her to perform as the hard body that is evidently central to bringing about the ultimate resolution to the battle of the day. As this article could not focus extensively on the intersectional dimensions of of the Avengers, it would be worthwhile for future research to elucidate these aspects in light of the uncertainties of the 2010s. The follow-up movies Infinity War (2018) and Endgame (2019) should offer a fertile ground for investigating the cinematic representation and realization of oppressed groups in superhero movies, while also offering updated takes on the broader ambiguities that were discussed in this work.

\section{References}

Barthes, R. (1972). Mythologies. London: Paladin.

Baudrillard, J. (2001). The Precession of Simulacra. In: V. B. Leitch. (ed.), The Norton Anthology of Theory and Criticism, New York: Norton, 1483-1491.

Bograd, N. K. (2015). "Nothing's Been the Same Since New York:" The Marvel Cinematic Universe's Engagement With 9/11 and the War on Terror. Texas ScholarWorks. University of Texas Libraries. (30 September 2019) <https:// repositories.lib.utexas.edu/handle/2152/32090>.

Braudy, L. (2003). From Chivalry to Terrorism: War and The Changing Nature of Masculinity. New York: Alfred A. Knopf.

Brody, R. (2015). The New "Avengers" Is Really About the N.S.A. The New Yorker. (29 September 2019) <https://www.newyorker.com/culture/richard-brody/thenew-avengers-is-really-about-the-n-s-a $>$.

Cox, C. (2018). Autonomous Exchanges: Human-Machine Autonomy in the Automated Media Economy. ScholarWorks@Georgia State University. Georgia State University Library. (29 September 2019) <https://scholarworks.gsu.edu/fmt_ dissertations/5>. 
Fleming, M. J. (2015). The Avengers Disassembled: Deconstructing Gender and Hegemonic Masculinity in Superhero Culture. Social Justice and Community Engagement, 8 -Scholars Commons@ Laurier. Wilfried Laurier University. (30 September 2019)<http://scholars.wlu.ca/brantford_sjce/8>.

Foster, C. (2013). Marvel vs DC: Mergers, Acquisitions and Corporate Rebranding in the New Millennium. CINEPHILE, The University of British Columbia's Film Journal, 9(2), Fall, 12-20. (30 September 2019) <http://cinephile.ca/wpcontent/uploads/9.2-WEB-VERSION.pdf .

Gruenewald, T. (2018). Superhero Films After 9/11: Mitigating 'Collateral Damage.' in the Marvel Cinematic Universe. In: T. Gruenewald and S. Laderman (eds.), Imperial Benevolence: U.S. Foreign Policy and American Popular Culture since 9/11, Los Angeles, CA: University of California Press, 141-167.

Hagley, A. and M. Harrison (2014). The Resurgent Superhero Genre in Film Gives Insights into The American Psyche and Political Identities Post-September 11. LSE American Politics and Policy. (29 September 2019) <https://blogs.lse. ac.uk/usappblog/2014/01/20/avengers-politics/>.

Hammer, R. and D. Kellner (2009). Media/Cultural Studies: Critical Approaches. New York: Peter Lang Publishing, Inc.

Hassler-Forest, D. (2012). Capitalist Superheroes: Caped Crusaders in the Neoliberal Age. Alresford: Zero Books.

Jeffords, S. (1994). Hard Bodies: Hollywood Masculinity in the Reagan Era. New Brunswick: Rutgers University Press.

Kaplan, E. A. (2005). Trauma Culture: The Politics of Terror and Loss in Media and Literature. New Brunswick: Rutgers University Press.

Kellner, D. (1995). Media Culture: Cultural Studies, Identity and Politics between the Modern and the Post-modern. New York: Routledge.

Kellner, D. (2003). 9/11, Spectacles of Terror, and Media Manipulation: A Critique of Jihadist and Bush Media Politics. Graduate School of Education \& Information Studies, UCLA. University of California, Los Angeles. (29 September 2019) $<$ https://pages.gseis.ucla.edu/faculty/kellner/essays/911terrorspectaclemedia.pdf $>$.

Kellner, D. (2003). Media Spectacle. London: Routledge.

Kellner, D. (2009). Cinema Wars: Hollywood Film and Politics in the Bush-Cheney Era. Chichester: Wiley-Blackwell.

Kosal, M. E. (2018). Technology and the Intelligence Community: Challenges and Advances for the 21st Century. Cham: Springer.

Kosović, M. (2011). Revisiting the Society of the Spectacle in the post-9/11 World. Contemporary Issues, 4(1), 18-28. (30 September 2019) <https://hrcak.srce.hr/ file/113116>. 
Lee, C. (2014). In 2015, Artificial Intelligence Will Rule The (Movie) World. Entertainment Weekly. (29 September 2019) <https://ew.com/article/2014/12/22/ aventers-ultron-terminator-genisys-artificial-intelligence/?hootPostID $=5 \mathrm{f} 8 \mathrm{e} 8 \mathrm{e} 7$ 1ea7b22b98052ad7e5da5f018>.

McEnteggart, S. (2010). Sequelizing the Superhero. Postmillenial Anxiety and Cultural Need. In: C. Jess-Cook and C. Verevis (eds.), Second Takes. Critical Approaches to the Film Sequel, New York: State University of New York Press, 171-189.

Milkman, R. (2017). A New Political Generation: Millennials and the Post-2008 Wave of Protest. American Sociological Review, 82(1), 1-31. (30 September 2019) $<$ http://journals.sagepub.com/doi/pdf/10.1177/0003122416681031>.

Moon, M. (2016). Thought We Wouldn't Notice, But We Did: An Analysis of Critical Transmedia Literacy Among Consumers of The Marvel Cinematic Universe. Texas A\&M University-Corpus Christi. (30 September 2019) <https://tamuccir.tdl.org/bitstream/handle/1969.6/678/Moon\%2c\%20Meghan\%20thesis. pdf? sequence $=1$ \&isAllowed $=\mathrm{y}>$.

Murphy, J. N. (2015). The Role of Women in Film: Supporting the Men - An Analysis of how Culture Influences the Changing Discourse on Gender Representations in Film.ScholarWorks@UARK - University of Arkansas. (30 September 2019) $<$ http://scholarworks.uark.edu/jouruht/2>.

Nielsen, L. (2017). Marvel Films as Effective Cinema Therapy. Cinesthesia, 7(1), 1-6. (30 September 2019) <https://scholarworks.gvsu.edu/cgi/viewcontent. cgi? article $=1131 \&$ context $=$ cine $>$.

Plantinga, C. (2009). Moving Viewers: American Film and the Spectator's Experience. Berkeley and Los Angeles: University of California Press.

Political Polarization in the American Public. (2014). Pew Research Center U.S. Politics \& Policy. (29 September 2019) <https://www.people-press.org/2014/06/12/ political-polarization-in-the-american-public/>.

Ranogajec, P. (2018). Skyscrapers, Cars, and American ambition: The Chrysler Building. Smarthistory. (30 September 2019) <https://smarthistory.org/chryslerbuilding-sa/s.

Said, E. (2003). Orientalism. New York: Penguin Books.

Schulz, S. (2013). Nostalgia in Contemporary Superhero Movies. University of Amsterdam. (29 September 2019) <http://scriptiesonline.uba.uva.nl/ document $/ 513359>$.

Strongman, L. (1996). Post-Colonialism or Post-Imperialism? Deep South, 2(3), Spring. (30 September 2019) <https://www.otago.ac.nz/deepsouth/vol2no3/ post-col.html>. 
Van Der Werff, T. (2016). How Marvel Films like Captain America: Civil War Became the World's Biggest TV Show. Vox. (23 September 2019) <https://www.vox. com/2016/5/12/11654248/captain-america-civil-war-batman-v-supermanmarvel-tv>.

Wolf-Meyer, M. J. (2006). Batman and Robin in the Nude, or Class and its Exceptions. Extrapolation, 47(2), Summer, 187-206. (30 September 2019) <https:// nequalsone.files.wordpress.com/2013/02/wolf-meyer-2006b.pdf >.

Wood, R. (2003). Hollywood from Vietnam to Reagan... and Beyond. New York: Columbia University Press.

Zakaria, F. (2011). Fareed Zakaria on Donald Trump and Coded Racism. Global Public Square. CNN. (30 September 2019) <http://globalpublicsquare.blogs. cnn.com/2011/04/22/fareed-zakaria-on-the-donald-trump-fantasy/>.

Žižek, S. (2009). First as Tragedy, Then as Farce. London and New York: Verso. 